\title{
An Investigation into How Reverberation Effects the Space of Instrument Emotional Characteristics
}

\author{
RONALD MO', RICHARD H. Y. SO², AND ANDREW HORNER, ${ }^{3}$ AES Member \\ (ronmo@cse.ust.hk) (rhyso@ust.hk) (horner@cse.ust.hk) \\ ${ }^{1}$ Department of Computer Science and Engineering, Hong Kong University of Science and Technology, \\ Clear Water Bay, Kowloon, Hong Kong \\ ${ }^{2}$ Department of Industrial Engineering and Logistics Management, Hong Kong University of Science and Technology, \\ Clear Water Bay, Kowloon, Hong Kong \\ ${ }^{3}$ Department of Computer Science and Engineering, Hong Kong University of Science and Technology, \\ Clear Water Bay, Kowloon, Hong Kong
}

\begin{abstract}
Previous research has shown that musical instruments have distinctive emotional characteristics [1-9] and that these characteristics can be significantly changed with reverberation [10-13]. This paper considers whether these changes in character are relatively uniform or instrument-dependent. We compared eight sustained instrument tones with different amounts and lengths of simple parametric reverberation over eight emotional characteristics. The results show a remarkable consistency in listener rankings of the instruments for each of the different types of reverberation, with strong correlations ranging from 90 to $95 \%$. These results indicate that the underlying instrument space does not change much with reverberation in terms of emotional characteristics, and that each instrument has a particular footprint of emotional characteristics. Among the tones we tested, the instruments cluster into two fairly distinctive groups: those where the positive energetic emotional characteristics are strong (e.g., oboe, trumpet, violin) and those where the low-arousal characteristics are strong (e.g., bassoon, clarinet, flute, horn). The saxophone is an outlier and is somewhat strong for most emotional characteristics. In terms of applications, the relatively consistent rankings of emotional characteristics between the instruments certainly helps each instrument retain its identity in different reverberation environments and suggests possible future work in instrument identification.
\end{abstract}

\section{INTRODUCTION}

Researchers have considered various relationships between timbre and music emotion [14-29] and, in particular, have found that dfferent instruments have different timbral and emotional characteristics [1-8]. By changing the pitch, dynamics, and other aspects of the performance, the timbre and emotional characteristics also change [9, 30-36]. These characteristics are further modified by the performance environment - by the amount and length of reverberation in the space $[10,11,37,38]$, which smears the temporal and spectral envelopes and changes the emotional character of the sound. The same idea holds when artificial reverberation is added as a post-process. For example, concert hall reverberation can bring out emotional characteristics such as Mysterious or Heroic from the original studio recording, or the recording engineer and musicians might use a dry sound to emphasize its Comic character [12].

While reverberation can strengthen or deemphasize particular emotional characteristics, does it change the under- lying instrument space? In other words, when reverberation changes the emotional characteristics of the instruments, does it change them uniformly or some instruments more than others? If we compare the instruments in terms of the emotional characteristic Heroic, for example, and rank them, is the ranking about the same for different amounts and lengths of reverberation? Or, does a bright instrument such as the trumpet increase more in its Heroic character with more reverberation compared to darker instruments such as the horn? These questions have not been investigated previously to our knowledge, even though they have some implications in timbre and music emotion research.

This paper will address these issues by comparing eight sustaining instruments over eight emotional characteristics with different amounts and lengths of reverberation. For each reverberation type and emotional characteristic, we will compare the instruments pairwise and establish a ranking based on statistical methods. We will then correlate the rankings to determine their similarity. We will also determine statistically significant differences between the instruments using paired t-tests. 
This will allow us to judge changes to the instruments in the underlying space of emotional characteristics with different reverberation amounts and lengths for simple parametric reverberation. Future work can consider other types of reverberation such as plate reverberation and impulse reverberation.

So, our main objective is to answer the question: does reverberation change the emotional characteristics of instruments uniformly in about the same way, or is the result instrument-dependent? The answer to this question is interesting in itself from the standpoint of music emotion and timbre. Certainly each instrument has a distinct timbre in the sense that a clarinet is identifiable to musicallytrained listeners in an anechoic chamber, a practice room, a recital hall, and a large concert hall. The spectral and temporal envelopes of the clarinet are different depending on the room reverberation, but the instrument identity remains unchanged. Similarly, are there distinctive emotional characteristics for each instrument? In other words, for each emotional characteristic, is there a relatively consistent ranking between the instruments that holds up under different types of reverberation? Is there a footprint of emotional characteristics for each instrument? If not, then in each performance environment the instruments will assume different characters, which helps explain their rich versatility. On the other hand, if there is a unique footprint for each instrument, it helps explain why performers can practice in small rehearsal rooms and reasonably predict the emotional blends and balances between the instruments even when the final performance is in a large concert hall (perhaps with some minor adjustments). In either case, the results will be interesting.

This work also has implications for music emotion research of single musical instrument tones. Most of the sample libraries contain tones with light reverberation (e.g., The McGill University Master Samples Collection [39], Prosonus Sound Library [40], RWC Music Database [41]), and there are only a limited number of anechoic samples available (e.g., University of Iowa Musical Instrument Samples [42]). Most timbre and music emotion studies of single instrument tones do not explicitly state whether the tones are anechoic or with light reverberation, and assume that it does not matter too much. Is this a safe assumption? It would be useful to know. If reverberation changes the emotional characteristics of instruments uniformly in about the same way, then the relative space of emotional characteristics between the instruments stays about the same with different reverberations. In this situation, we can use the numerous samples that have light reverberation to compare instruments in terms of their emotional characteristics and expect about the same relative characteristics if they had been recorded in an anechoic chamber or a hall with different reverberation. On the other hand, if the change of emotional characteristics is instrumentdependent with reverberation, then the situation is more complicated. It would indicate a strong dependence on the type of reverberation, and suggests the limited applicability of studies of single instrument tones only to tones with similar types of reverberation. In this case, it would also suggest the need for more anechoic sample libraries.

To clarify these issues, this study will systematically explore the question of whether reverberation changes the emotional characteristics of instruments uniformly in a similar way or whether it is instrument-dependent.

\section{METHODOLOGY}

\subsection{Overview}

For this investigation, we used a relatively simple parametric reverberation model to measure the emotional characteristics of instruments for two of the most important reverberation parameters: reverberation length and amount. Future experiments with other reverberation parameters and models will further deepen our understanding, but reverberation length and amount provide an obvious starting place. Through a listening test with paired comparisons and statistical analysis we will investigate whether simple parametric reverberation changes the emotional characteristics of instruments uniformly or in an instrument-dependent way.

To address this question, we conducted a listening test to compare instruments in order to determine how the ranking of the instruments varied with different types of reverberation and different emotional characteristics. We tested eight sustained musical instruments representing the wind and bowed string families. We compared these sounds over eight emotional categories used in previous studies [3-9, $12,43-47]$ and that are commonly expressed by composers in tempo and expression marks (Happy, Sad, Heroic, Scary, Comic, Shy, Romantic, and Mysterious). The following section describes the details of the listening test.

\subsection{Listening Test}

Our test had listeners compare eight instrument tones over eight emotional categories for each type of reverberation. The basic stimuli consisted of eight sustained wind and bowed string instrument sounds without reverberation: bassoon (bs), clarinet (cl), flute (fl), horn (hn), oboe (ob), saxophone (sx), trumpet (tp), and violin (vn). They were obtained from the University of Iowa $\mathrm{Mu}$ sical Instrument Samples [42]. These sounds were all recorded in an anechoic chamber and were thus free from reverberation.

The sustained instruments are nearly harmonic and the chosen sounds had fundamental frequencies close to Eb4 $(311.1 \mathrm{~Hz})$. They were analyzed using a phase-vocoder algorithm where bin frequencies were aligned with the signal's harmonics [48]. Attacks, sustains, and decays were equalized by time-compression/expansion of the amplitude envelopes to $0.05 \mathrm{~s}, 0.8 \mathrm{~s}$, and $0.15 \mathrm{~s}$ respectively, for a total duration of $1.0 \mathrm{~s}$. The sounds were resynthesized by additive sinewave synthesis at exactly $311.1 \mathrm{~Hz}$. Since loudness is a potential factor in emotional characteristics, the sounds were equalized in loudness by manual adjustment. 


\begin{tabular}{lccc}
\hline \hline Hall Type and Position & $\begin{array}{c}\text { Reverb } \\
\text { Length }\end{array}$ & $\begin{array}{c}\text { Reverb } \\
\text { Amount }\end{array}$ & $R T_{60}$ \\
\hline Small Hall Front & $1 \mathrm{~s}$ & $20 \%$ & 0.95 \\
Small Hall Back & $1 \mathrm{~s}$ & $80 \%$ & 1.28 \\
Large Hall Front & $2 \mathrm{~s}$ & $20 \%$ & 1.78 \\
Large Hall Back & $2 \mathrm{~s}$ & $80 \%$ & 2.37 \\
\hline
\end{tabular}

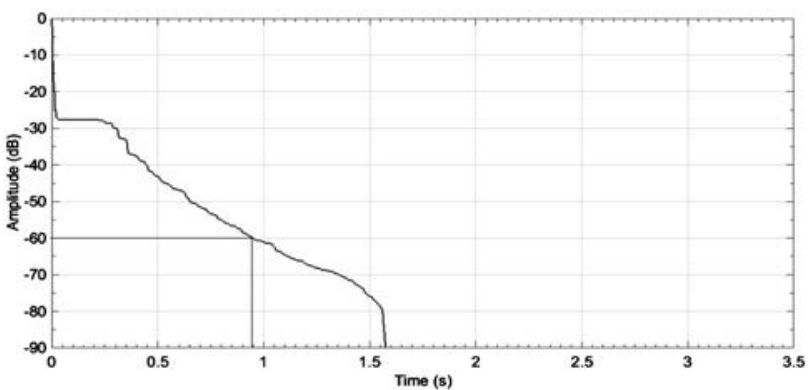

Fig. 1. Impulse response and $R T_{60}$ for Small Hall Front

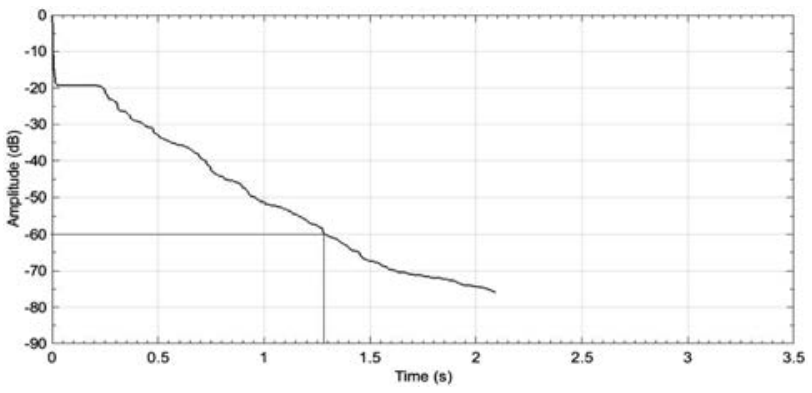

Fig. 2. Impulse response and $R T_{60}$ for Small Hall Back

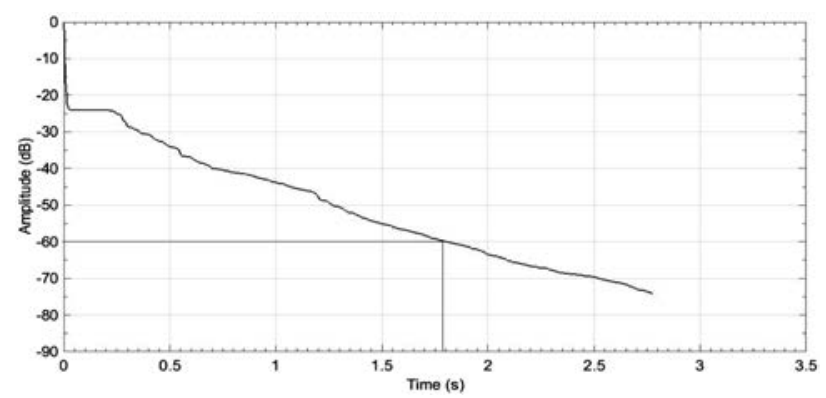

Fig. 3. Impulse response and $R T_{60}$ for Large Hall Front

In addition to the resynthesized anechoic sounds, we compared sounds with reverberation lengths of $1 \mathrm{~s}$ and $2 \mathrm{~s}$, which according to Hidaka and Beranek [49] and Beranek [50] typically correspond to small and large concert halls. We used the reverberation generator provided by Cool Edit [51]. Its "Concert Hall Light" preset is a reasonably natural sounding reverberation. This preset uses $80 \%$ for the amount of reverberation corresponding to the back of the hall, and we approximated the front of the hall with $20 \%$. Thus, in addition to the dry sounds, there were four types of reverberation :

Figs. 1 to 4 show the impulse responses and $R T_{60}$ values for the different types of reverberation we used. The Early

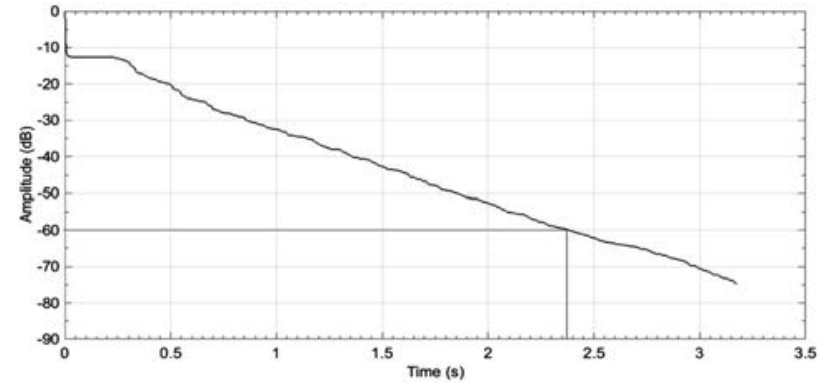

Fig. 4. Impulse response and $R T_{60}$ for Large Hall Back

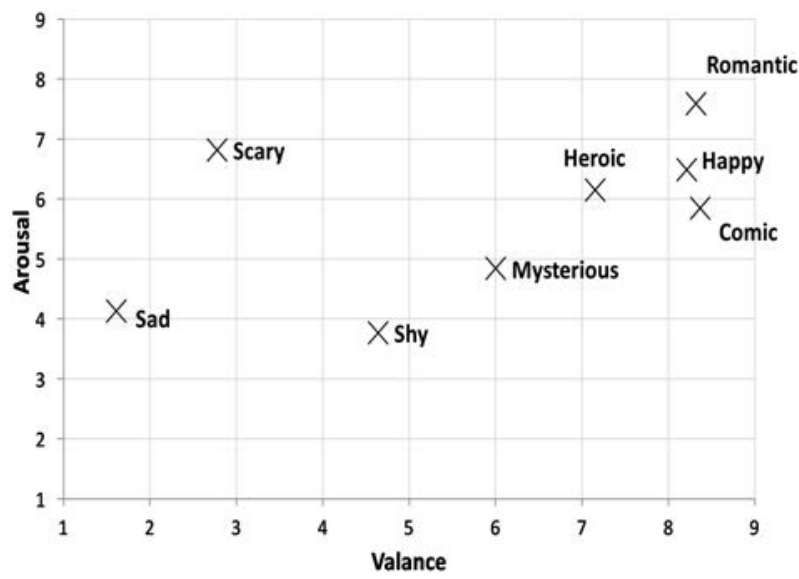

Fig. 5. Distribution of the emotional characteristics in the dimensions Valence and Arousal. The Valence and Arousal values are given in the 9-point rating in ANEW [53]. Valence shows the positiveness of an emotional category; Arousal shows the energy level of an emotional category.

Decay Time (EDTs) were near-zero for all four reverberation types.

We hired 36 subjects to take the listening test. All subjects were fluent in English. They were all undergraduate students at the Hong Kong University of Science and Technology where all courses are taught in English. Among the 36 subjects, there were 24 males and 12 females. The subjects ranged in age from 19 to 27 . In terms of musical experience, 17 subjects had some experience playing an instrument (an average of 4.8 years), and 19 subjects did not have experience playing an instrument. In recruiting the subjects, all 36 indicated they had no known hearing problems.

The subjects compared the stimuli in paired comparisons for eight emotional categories: Happy, Sad, Heroic, Scary, Comic, Shy, Romantic, and Mysterious. Some choices of emotional characteristics are fairly universal and occur in many previous studies (e.g., Happy, Sad, Scary/Fear/Angry, Tender/Calm/Romantic) roughly corresponding to the four quadrants of the Valence-Arousal plane, but there are lots of variations beyond that [52]. For this study we used the same categories we have used in our previous research on musical instruments [3-9, 12]. The ratings of the emotional categories according to the Affective Norms for English Words [53] are shown in Fig. 5 using the Valence-Arousal model. Valence shows the positiveness of an emotional 


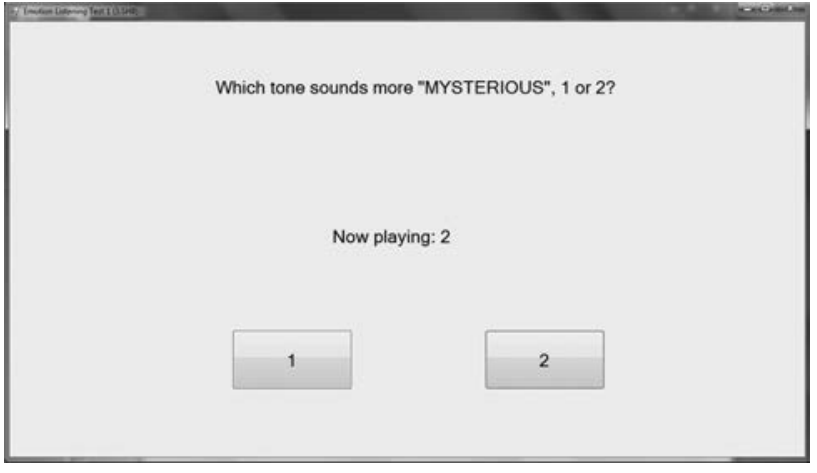

Fig. 6. Paired comparison listening test interface

category; Arousal shows the energy level of an emotional category. Happy, Comic, Heroic, and Romantic form a clusterbut they represent distinctly different emotional categories.

In the listening test, every subject heard paired comparisons of all eight instruments for each type of reverberation and emotional category. During each trial, subjects heard a pair of instrument sounds from the same type of reverberation and were prompted to choose which more strongly aroused a given emotional category. Since each trial was a single paired comparison requiring minimal memory from the subjects, subjects did not need to remember all of the tones, just the two in each comparison. Fig. 6 shows a screenshot of the paired comparison listening test interface. One big advantage of using paired comparisons of emotional categories is that it allows faster decision-making by the subjects. Paired comparison is also a simple decision and is easier than absolute rating.

Each combination of two different instrument tones were presented for each of the five reverberation types and eight emotional categories, and the listening test totaled $C_{2}^{8} \times$ $5 \times 8=1120$ trials. For each instrument, the overall trial presentation order was randomized. For the two sounds A and $\mathrm{B}$, they heard $\mathrm{AB}$ where the order of $\mathrm{A}$ and $\mathrm{B}$ was random for each comparison (but if they heard $\mathrm{AB}$, they did not hear BA later).

Before the first trial, subjects read online definitions of the emotional categories from the Cambridge Academic Content Dictionary [54]. The dictionary definitions we used in our experiment are shown in Table 1. Subjects were not musical experts (e.g., recording engineers, professional musicians, or music conservatory students) but average attentive listeners. The listening test took about 2 hours, with breaks every 30 minutes.

The subjects were seated in a "quiet room" with $39 \mathrm{~dB}$ SPL background noise level (mostly due to computers and air conditioning). The noise level was reduced further with headphones. Sound signals were converted to analog by a Sound Blaster X-Fi Xtreme Audio sound card and then presented through Sony MDR-7506 headphones. The Sound Blaster DAC utilizes 24 bits with a maximum sampling rate of $96 \mathrm{kHz}$ and a $108 \mathrm{~dB} \mathrm{~S} / \mathrm{N}$ ratio. We felt that basic-level professional headphones were adequate in representing the simple reverberated sounds for this test as the lengths and
Table 1 . The dictionary definitions of the emotional categories used in our experiment.

\begin{tabular}{ll}
\hline Emotional Category & \multicolumn{1}{c}{ Definition } \\
\hline Happy & Glad, pleased \\
Sad & $\begin{array}{c}\text { Affected with or expressive of } \\
\text { grief or unhappiness } \\
\text { Exhibiting or marked by courage } \\
\text { and daring } \\
\text { Heroic }\end{array}$ \\
Causing fright \\
Comic & Causing laughter or amusement \\
Shy & Disposed to avoid a person or \\
thing & Relating to love or loving \\
Romantic & relationship \\
Mysterious & Strange or unknown \\
\hline
\end{tabular}

amounts of reverberation were quite different and readily distinguishable. A big advantage of the Sony MDR-7506 headphones is their relative comfort in a relatively long listening test such as this one, especially for subjects not used to tight-fitting studio headphones.

\section{RESULTS FOR THE EMOTIONAL CHARACTERISTICS WITH DIFFERENT TYPES OF REVERBERATION}

For our listening test, listeners compared each pair of instruments for each emotional category and each reverberation type. Originally, we had 36 subjects since the test was rather long at 2 hours. We screened the responses and found 3 subjects were obviously spanning the same key responses toward the end of the test, so we excluded all of their data. We scanned the remaining subjects' data, especially at the end of the test, and based on the consistency of their responses, felt that they were giving sincere and attentive responses to the questions, so we did not exclude any further subjects.

Based on the filtered listening test data of 33 subjects, we derived scale values using the Bradley-Terry-Luce (BTL) statistical model $[55,56]$. Figs. 7 to 11 show the BTL scale values and the corresponding $95 \%$ confidence intervals for each reverberation type (anechoic, small hall front, small hall back, large hall front, and large hall back respectively). For each graph, the BTL scale values for the eight instruments sum up to 1 . The BTL value for each instrument is the probability that listeners will choose that instrument when considering a certain reverberation type and emotion category. For example, if all eight instruments (Bs, Cl, Fl, $\mathrm{Hn}, \mathrm{Ob}, \mathrm{Tp}, \mathrm{Sx}$, and $\mathrm{Vn}$ ) were judged equally Happy, the BTL scale values would be $1 / 8=0.125$.

Though there are certainly differences between Figs. $7-$ 11 , overall they are remarkably similar to one another. For example, the trumpet was consistently ranked highest for Heroic with all reverberation types, while the clarinet was ranked highest for Sad. Going further, the trumpet ranked the highest for all five reverberation types for Happy, Heroic, and Comic, while the clarinet was highest for Sad, Shy, Romantic, and Mysterious (except a close 

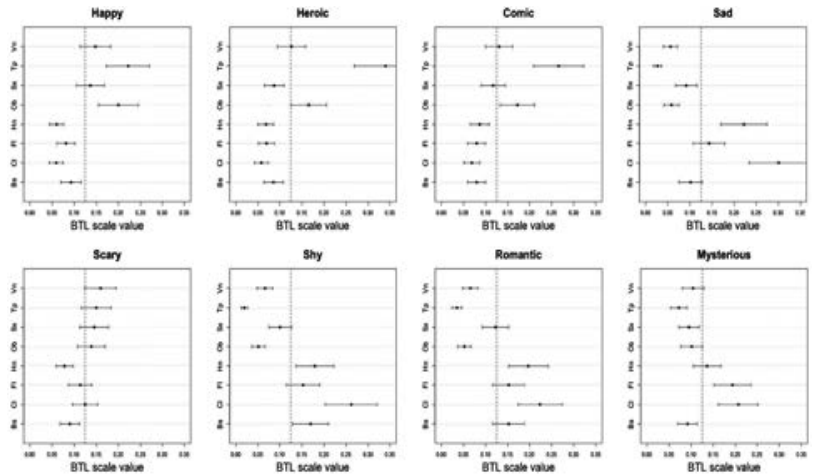

Fig. 7. BTL scale values and the corresponding $95 \%$ confidence intervals of the original anechoic instrument sounds for each emotional characteristic. The dotted line represents the average, with instrument sounds to the right more Happy, for example, and instrument sounds to the left less.

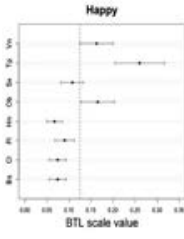

serry
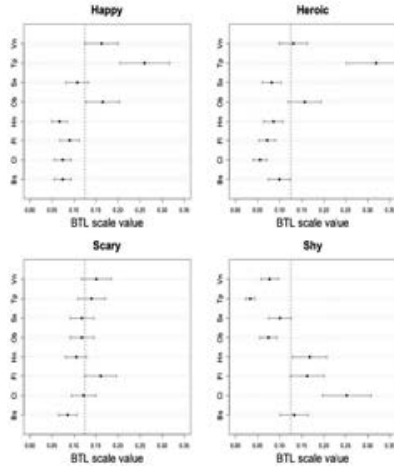

shy
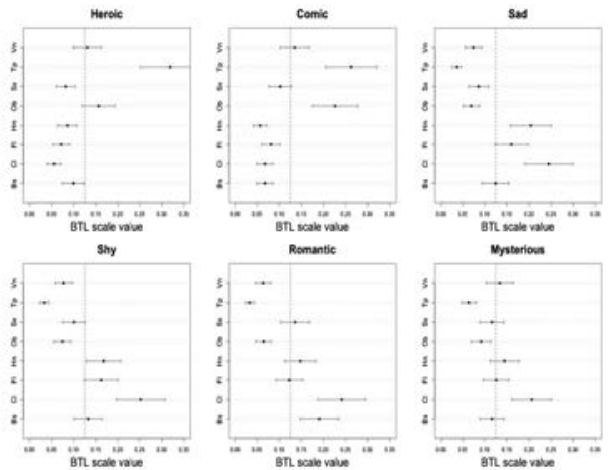

Fig. 8. BTL scale values and the corresponding 95\% confidence intervals of the instrument sounds with Small Hall Front reverberation for each emotional characteristic.
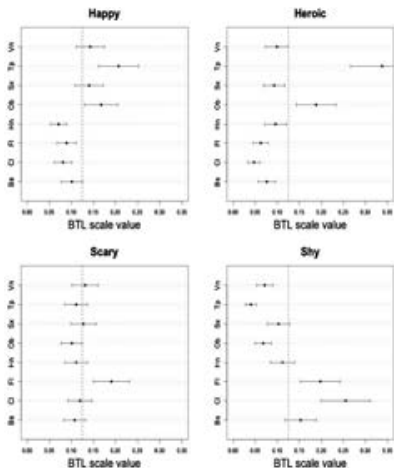
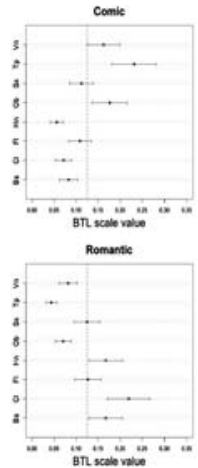
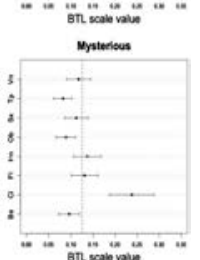

Fig. 9. BTL scale values and the corresponding $95 \%$ confidence intervals of the instrument sounds with Small Hall Back reverberation for each emotional characteristic.

second for Small Hall Front), and the flute and violin shared top-rankings for Scary. Heroic consistently had the widest range among all reverberation types and Scary the narrowest.

We wanted to determine the number of times each instrument was significantly greater than the other seven instruments for each reverberation type and emotional char-
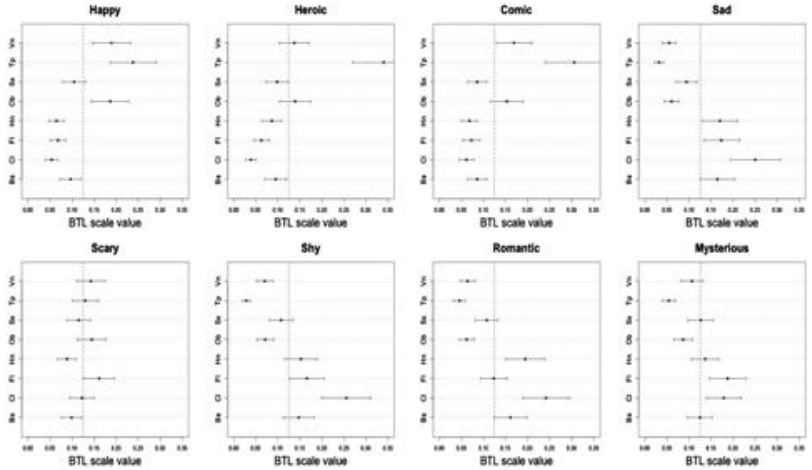

Fig. 10. BTL scale values and the corresponding 95\% confidence intervals of the instrument sounds with Large Hall Front reverberation for each emotional characteristic.
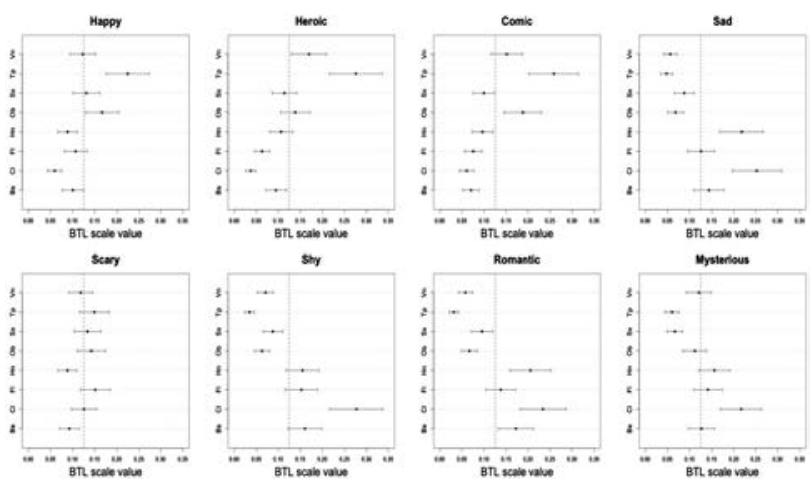

Fig. 11. BTL scale values and the corresponding 95\% confidence intervals of the instrument sounds with Large Hall Back reverberation for each emotional characteristic.

acteristic. As a preliminary step, the normality of the data was calculated for each instrument, emotional characteristic, and reverberation type. Since most, though not all, were normally distributed (see Tables 5-9 in Appendix A), both parametric and nonparametric statistical tests (parametric: Paired t-tests, Pearson correlation; nonparametric: Wilcoxon signed-rank tests, Spearman correlation) were used to analyze the voting data (i.e., the number of positive votes received by each instrument for each emotional category and reverberation type). The results from the two tests showed some minor differences but basically they were in agreement. Table 2 shows the paired t-test results and Table 10 in Appendix B shows the Wilcoxon signed-rank test results. For each instrument, the maximum possible value is 7 and the minimum possible value is 0 . For example, with the original anechoic sounds and the emotional characteristic Heroic, the value of the trumpet is 7 since it was statistically significantly greater than all seven of the other instruments for the Heroic subgraph in Fig. 7. The maximum value for each reverberation type and emotional characteristic is shown in bold for both tables.

Table 3 sums the sub-tables in Table 2 and shows the number of times each instrument was significantly greater than the other seven instruments over all five reverberation types for each emotional characteristic. The maximum pos- 
Table 2. Based on paired t-tests, how often each instrument was statistically significantly greater (for $p<0.05$ ) than the others for each reverberation type and emotional characteristic. The maximum possible value is 7 and the minimum possible value is 0 . The maximum for each reverberation type and emotional characteristic is shown in bold.

\begin{tabular}{|c|c|c|c|c|c|c|c|c|c|c|c|c|c|c|c|c|}
\hline \multicolumn{9}{|c|}{ Anechoic } & \multicolumn{8}{|c|}{ Small Hall Front } \\
\hline & Bs & $\mathrm{Cl}$ & $\mathrm{Fl}$ & $\mathrm{Hn}$ & $\mathrm{Ob}$ & Sx & $\mathrm{Tp}$ & Vn & Bs & $\mathrm{Cl}$ & $\mathrm{Fl}$ & $\mathrm{Hn}$ & $\mathrm{Ob}$ & Sx & $\mathrm{Tp}$ & Vn \\
\hline Happy & 2 & 0 & 0 & 0 & 4 & 3 & 4 & 3 & 0 & 0 & 0 & 0 & 5 & 1 & 7 & 5 \\
\hline Heroic & 0 & 0 & 0 & 0 & 5 & 0 & 7 & 3 & 1 & 0 & 0 & 0 & 5 & 0 & 7 & 3 \\
\hline Comic & 0 & 0 & 0 & 0 & 4 & 2 & 7 & 2 & 0 & 0 & 0 & 0 & 6 & 3 & 6 & 4 \\
\hline Sad & 3 & 6 & 3 & 6 & 1 & 2 & 0 & 1 & 3 & 6 & 4 & 5 & 1 & 1 & 0 & 1 \\
\hline Scary & 0 & 1 & 0 & 0 & 1 & 2 & 1 & 2 & 0 & 0 & 2 & 0 & 0 & 0 & 0 & 1 \\
\hline Shy & 4 & 6 & 4 & 4 & 1 & 3 & 0 & 1 & 2 & 7 & 4 & 4 & 1 & 1 & 0 & 1 \\
\hline Romantic & 3 & 5 & 3 & 3 & 0 & 3 & 0 & 1 & 4 & 5 & 3 & 3 & 1 & 3 & 0 & 1 \\
\hline Mysterious & 0 & 6 & 5 & 1 & 0 & 0 & 0 & 0 & 1 & 5 & 1 & 1 & 0 & 1 & 0 & 1 \\
\hline \multicolumn{9}{|c|}{ Small Hall Back } & \multicolumn{8}{|c|}{ Large Hall Front } \\
\hline & Bs & $\mathrm{Cl}$ & $\mathrm{Fl}$ & $\mathrm{Hn}$ & $\mathrm{Ob}$ & Sx & $\mathrm{Tp}$ & $\mathrm{Vn}$ & Bs & $\mathrm{Cl}$ & $\mathrm{Fl}$ & $\mathrm{Hn}$ & $\mathrm{Ob}$ & Sx & $\mathrm{Tp}$ & Vn \\
\hline Happy & 0 & 0 & 0 & 0 & 4 & 3 & 4 & 3 & 2 & 0 & 0 & 0 & 5 & 2 & 5 & 5 \\
\hline Heroic & 1 & 0 & 0 & 1 & 6 & 2 & 7 & 1 & 2 & 0 & 1 & 1 & 3 & 1 & 7 & 2 \\
\hline Comic & 1 & 0 & 2 & 0 & 5 & 2 & 5 & 3 & 0 & 0 & 0 & 0 & 5 & 0 & 7 & 5 \\
\hline Sad & 3 & 5 & 5 & 5 & 1 & 2 & 0 & 1 & 4 & 4 & 4 & 4 & 1 & 3 & 0 & 1 \\
\hline Scary & 0 & 0 & 4 & 0 & 0 & 0 & 0 & 0 & 0 & 0 & 2 & 0 & 0 & 0 & 0 & 0 \\
\hline Shy & 3 & 6 & 5 & 1 & 1 & 1 & 0 & 1 & 3 & 7 & 4 & 3 & 1 & 3 & 0 & 1 \\
\hline Romantic & 3 & 5 & 3 & 3 & 1 & 3 & 0 & 1 & 4 & 5 & 3 & 5 & 0 & 3 & 0 & 0 \\
\hline Mysterious & 0 & 7 & 0 & 1 & 0 & 0 & 0 & 0 & 1 & 2 & 4 & 1 & 1 & 1 & 0 & 1 \\
\hline \multicolumn{9}{|c|}{ Large Hall Back } & & & & & & & & \\
\hline & Bs & $\mathrm{Cl}$ & $\mathrm{Fl}$ & $\mathrm{Hn}$ & $\mathrm{Ob}$ & Sx & $\mathrm{Tp}$ & Vn & & & & & & & & \\
\hline Happy & 1 & 0 & 1 & 0 & 3 & 1 & 6 & 1 & & & & & & & & \\
\hline Heroic & 2 & 0 & 1 & 2 & 2 & 2 & 6 & 3 & & & & & & & & \\
\hline Comic & 0 & 0 & 0 & 1 & 5 & 1 & 6 & 4 & & & & & & & & \\
\hline Sad & 4 & 6 & 4 & 6 & 0 & 2 & 0 & 0 & & & & & & & & \\
\hline Scary & 0 & 0 & 2 & 0 & 0 & 0 & 0 & 0 & & & & & & & & \\
\hline Shy & 4 & 7 & 4 & 4 & 1 & 1 & 0 & 1 & & & & & & & & \\
\hline Romantic & 4 & 5 & 3 & 4 & 1 & 2 & 0 & 1 & & & & & & & & \\
\hline Mysterious & 2 & 6 & 2 & 2 & 2 & 0 & 0 & 2 & & & & & & & & \\
\hline
\end{tabular}

Table 3. How often each instrument was statistically significantly greater than the others over the five reverberation types. The maximum possible value is 35 and the minimum possible value is 0 . The maximum for each emotional characteristic is shown in bold. This table is simply the sum of the individual sub-tables in Table 2 .

\begin{tabular}{lcccccccc}
\hline \hline & Bs & $\mathrm{Cl}$ & $\mathrm{Fl}$ & $\mathrm{Hn}$ & $\mathrm{Ob}$ & $\mathrm{Sx}$ & $\mathrm{Tp}$ & $\mathrm{Vn}$ \\
\hline Happy & 5 & 0 & 1 & 0 & 21 & 10 & $\mathbf{2 6}$ & 17 \\
Heroic & 6 & 0 & 2 & 4 & 21 & 5 & $\mathbf{3 4}$ & 12 \\
Comic & 1 & 0 & 2 & 1 & 25 & 8 & $\mathbf{3 1}$ & 18 \\
Sad & 17 & $\mathbf{2 7}$ & 20 & 26 & 4 & 10 & 0 & 4 \\
Scary & 0 & 1 & $\mathbf{1 0}$ & 0 & 1 & 2 & 1 & 3 \\
Shy & 16 & $\mathbf{3 3}$ & 21 & 16 & 5 & 9 & 0 & 5 \\
Romantic & 18 & $\mathbf{2 5}$ & 15 & 18 & 3 & 14 & 0 & 4 \\
Mysterious & 4 & $\mathbf{2 6}$ & 12 & 6 & 3 & 2 & 0 & 4 \\
\hline
\end{tabular}

sible value is 35 and the minimum possible value is 0 . For example, for Heroic the trumpet was statistically significantly greater than all the other seven instruments for four reverberation types and six for Large Hall Back, so its value is 34 . The maximum value for each emotional characteristic is shown in bold. Table 3 makes it obvious that the trumpet was ranked the highest for Happy, Heroic, and Comic, the clarinet for Sad, Shy, Romantic, and Mysterious, and the flute for Scary.

We wanted to determine how similar were the sub-tables in Table 2 and the BTL data in Figs. 7-11 for the different reverberation types. Therefore, we ran correlations for both of these as well as for the voting data (i.e., the number of positive votes received by each instrument for emotional category and reverberation type). In all cases, the correlations were statistically significant (at the $p<0.0001$ level) and very strong, ranging from 90 to $95 \%$, indicating a nearlinear relationship and a very high level of agreement. In particular, Table 4 shows Pearson and Spearman correlation between the different reverberation types based on the voting data, since it is the most precise and direct measure of correlation in the sense that it is correlation of the original data and not correlation of statistics based on the original data (e.g., the BTL data in Figs. 7-11 and paired t-test data in Table 2).

Let's take another look at the question of the consistency of the listeners during this long 2-hour listening test. As further evidence that the 33 subjects were giving sincere and attentive responses, if they had been giving random responses at the end of the test due to fatigue, it would 
Table 4. Pearson and Spearman correlation between the different reverberation types based on the listener voting data.

\begin{tabular}{lcc}
\hline Reverberation Types & $\begin{array}{c}\text { Pearson } \\
\text { Correlation }\end{array}$ & $\begin{array}{c}\text { Spearman } \\
\text { Correlation }\end{array}$ \\
\hline Anechoic \& Small Hall Front & 0.944 & 0.930 \\
Anechoic \& Small Hall Back & 0.924 & 0.922 \\
Anechoic \& Large Hall Front & 0.946 & 0.941 \\
Anechoic \& Large Hall Back & 0.934 & 0.932 \\
Small Hall Front \& Small Hall Back & 0.946 & 0.944 \\
Small Hall Front \& Large Hall Front & 0.950 & 0.944 \\
Small Hall Front \& Large Hall Back & 0.927 & 0.917 \\
Small Hall Back \& Large Hall Front & 0.930 & 0.922 \\
Small Hall Back \& Large Hall Back & 0.902 & 0.897 \\
Large Hall Front \& Large Hall Back & 0.935 & 0.922 \\
\hline
\end{tabular}

have decreased the number of significant differences in Table 2, making the footprints less clear and less consistent. As it turned out, they were very consistent, suggesting listeners remained reasonably attentive. We don't claim that they were perfect, but the 90-95\% correlation in Table 4 indicates that listeners were amazingly consistent.

\section{DISCUSSION}

Previous work has shown that different musical instruments have distinct emotional characteristics [1-9], and that reverberation can greatly change these characteristics [10-12]. And while these emotional characteristics can be greatly changed with reverberation, the results in this paper have shown that they are changed uniformly in about the same way for different instruments. In other words, the underlying instrument space does not change much with reverberation in terms of emotional characteristics. For example, added reverberation might bring out characteristics such as Mysterious or Heroic, but in a uniform way for the instruments and not some more than others. There seems to be a relatively consistent ranking of emotional characteristics between the instruments that holds with different reverberation amounts and lengths, at least for simple parametric reverberation.

We should also emphasize that our results are for basiclevel professional headphones. Higher-quality professional headphones could perhaps show even more pronounced differentiation between the emotional characteristics though we expect it would also be in a uniform way for the instruments.

This uniformity is contrasting to our previous study [12] where distinct and significant changes occurred in every instrument and emotional characteristic with different types of reverberation. The strong distinct changes found in our first study led us to expect some instrument-dependencies in this study, which used exactly the same tones. But, the two studies are from contrasting perspectives. In our first study, tones with different types of reverberation were compared for each instrument and emotional characteristic, allowing us to identify which reverberation types heightened each emotional characteristic for each instrument. In this study, tones from different instruments were compared for each reverberation type and emotional characteristic, allowing us to rank the instruments for each reverberation type and emotional characteristic. There is no contradiction in their results: reverberation distinctly changes the character of the sound but does so in a uniform way across the instruments. It makes sense that reverberation changes the character uniformly across the instruments: if it were not uniform, then performers in orchestras and chamber groups would not be able to practice in small rehearsal rooms in a reliable way if reverberation affected the character in an instrumentdependent way. Musicians would need to carefully rehearse in the performance venue, not just to get used to the hall, but to adjust their blends and balances differently for each different venue.

The uniform effects of reverberation on instruments is in contrast to another post-process that we studied, MP3 compression, where the results were instrument-dependent [57]. There, the trumpet was much more effected than other instruments with more compression and the horn much less effected. But, for the tones we tested in our study of MP3 compression, the artifacts of excessive compression were obvious. If we had tested tones where the compression rate was lower, and the tones sounded the same as the original, we feel pretty confident that the emotional characteristics would have been the same as the original, and the instruments would have shown a trivially uniform response.

Admittedly, MP3 compression and reverberation are different. MP3 compression is a lossy process, and reverberation is in a sense an additive one-so it may be the results are simply different for the two processes. On the other hand, perhaps they are similar. Perhaps with concert hall levels reverberation the results are uniform, and with very large amounts or lengths of reverberation instrumentdependencies emerge. Why? It is not difficult to imagine that with excessive smearing of the temporal and spectral envelopes (e.g., a 5-second cathedral reverberation), that instruments with strong spectral variations in either the temporal or spectral envelopes (e.g., the clarinet with its strong odd harmonics) would be changed more than other instruments with smoother temporal or spectral envelopes (e.g., the horn). It is likely that the distinctive emotional characteristics of instruments such as the clarinet would erode in Tables 2 and 3 with very large amounts or lengths of reverberation. So, it may be that we did not happen to test a wide enough range of reverberations to be able to see the onset of these effects. Further work will be needed to confirm this. But it is remarkable how uniform the instruments were within the concert hall range of reverberation that we did test.

In any case, it will be interesting to see if these same overall results hold for other instruments, pitches, and dynamics, as we only tested Eb4-forte tones for eight instruments. It will also be interesting to see if these results hold for other types of reverberation such as plate reverberation and convolution reverberation, not just simple parametric reverberation.

More broadly, perhaps the relatively consistent ranking of emotional characteristics between the instruments is what allows each instrument to identify each instrument 
regardless of room reverberation, or at least helps. Perhaps each instrument has a characteristic footprint, that varies with pitch and dynamic level, which makes it identifiable.

So, where do these footprints appear in our data? The columns of each sub-table in Table 2 represent the footprints of the emotional characteristics for each instrument and reverberation type. In general, the footprints for each instrument were very similar for the different reverberation types (e.g., the trumpet had large values for Happy, Heroic, and Comic and small values for the others across all reverberation types).

The columns of Table 3 represent the overall footprints of the emotional characteristics for each instrument (for our Eb4-forte tones). The instruments clustered into two fairly distinct groups: those where the positive energetic emotional characteristics were strong (e.g., oboe, trumpet, violin), and those where the low-arousal characteristics were strong (e.g., bassoon, clarinet, flute, horn). The saxophone was an outlier, and was uniquely somewhat strong for most emotional characteristics. Looking in more detail, the oboe, trumpet, and violin had similar footprints, but the trumpet's footprints were deeper for Happy, Heroic, and Comic than the other two instruments. In the same way, the clarinet and horn had similar footprints, though the clarinet was deeper especially for Shy and Mysterious. The flute also had a similar footprint to the clarinet and horn, but was deeper for Scary. The bassoon was similar to the horn except deeper for Happy, less for Sad. The saxophone had the most even distribution, with medium values for most emotional categories.

As a disclaimer, probably the footprint for each instrument varies depending on its pitch and dynamics as well as other factors of each particular tone. What is useful to note here is that the footprints of each instrument for different types of reverberation were very similar, as we can see by comparing the respective columns for each sub-table in Table 2.

Anyway, the relatively consistent rankings of emotional characteristics between the instruments certainly helps explain why listeners can identify each instrument in different reverberation environments. This raises an interesting question about instrument identification: When listeners identify an instrument, are they identifying its unique sound, timbre, relative emotional characteristics, or a combination of these? This is a potential area for further work.

This work also has implications for music emotion research of single musical instrument tones, where most studies do not explicitly state whether the tones are anechoic or with light reverberation, and assume it does not matter too much. The results of this study suggest that this is a somewhat safe assumption if the relative emotional characteristics between instruments are the main consideration. Since reverberation changes the emotional characteristics of instruments uniformly in about the same way, then the relative space of emotional characteristics between the instruments will be maintained. So, we can use the numerous samples with light reverberation to compare instruments in terms of their emotional characteristics and expect about the same relative characteristics if they had been recorded in an anechoic chamber or a hall with different reverberation. Of course in other situations it really can make a difference. Since reverberation smears the temporal and spectral envelopes, it changes the timbre of the sound. Similarly, reverberation can greatly change the emotional characteristics of the sound. If changes in timbre or absolute emotional characteristics are the main consideration of the study, reverberation can indeed make a difference, and should be handled with caution and appropriate disclaimers should be included. In any case, it is useful to know which situations are relatively safe and which can be problematic.

Another great area for further work would be in the parameterization of the temporal and spectral envelope smearing of reverberation. With different amounts and lengths of reverberation, how much change can we expect in the temporal and spectral envelopes? Will it be uniform among different instruments as we found here, or instrumentdependent? To our knowledge, the temporal and spectral envelope smearing effects have not been parameterized in detail.

\section{ACKNOWLEDGMENTS}

Thanks to the anonymous reviewers for their valuable time in reviewing this paper.

\section{REFERENCES}

[1] K. R. Scherer and J. S. Oshinsky "Cue Utilization in Emotion Attribution from Auditory Stimuli," Motivation and Emotion vol. 1, no. 4, pp. 331-346 (1977). doi: http://dx.doi.org/10.1007/BF00992539

[2] T. Eerola, R. Ferrer, and V. Allure "Timbre and Affect Dimensions: Evidence from Affect and Similarity Ratings and Acoustic Correlates of Isolated Instrument Sounds," Music Perception: An Interdisciplinary J., vol. 30, no. 1, pp. 49-70 (2012). doi: http://dx.doi.org/10.1525/ mp.2012.30.1.49

[3] B. Wu, A. Horner, and C. Lee "Musical Timbre and Emotion: The Identification of Salient Timbral Features in Sustained Musical Instrument Tones Equalized in Attack Time and Spectral Centroid," International Computer Music Conference (ICMC), Athens, Greece (14-20 Sept. 2014), pp. 928-934.

[4] B. Wu, C. Lee, and A. Horner "The Correspondence of Music Emotion and Timbre in Sustained Musical Instrument Tones," J. Audio Eng. Soc., vol. 62, pp. 663-675 (2014 Oct.). doi: http://dx.doi.org/10.17743/jaes.2014.0037

[5] B. Wu et al., "Investigating Correlation between Musical Timbres and Emotions," International Society for Music Information Retrieval Conference (ISMIR), Curitiba, Brazil (2013), pp. 415-420.

[6] B. Wu, A. Horner, and C. Lee "Emotional Predisposition of Musical Instrument Timbres with Static Spectra," International Society for Music Information Retrieval Conference (ISMIR), Taipei, Taiwan, vol. 253-258 (2014 Nov.).

[7] C.-j. Chau, B. Wu, and A. Horner "Timbre Features and Music Emotion in Plucked String, Mallet Percussion, and Keyboard Tones," International Computer Music 
Conference (ICMC), Athens, Greece (14-20 Sept. 2014), pp. 982-989.

[8] C.-j. Chau, B. Wu, and A. Horner "The Emotional Characteristics and Timbre of Nonsustaining Instrument Sounds," J. Audio Eng. Soc., vol. 63, pp. 228-244 (2015 Apr.). doi: http://dx.doi.org/10.17743/jaes.2015.0016

[9] C.-j. Chau and A. Horner "The Effect of Pitch and Dynamics on the Emotional Characteristics of Piano Sounds," International Computer Music Conference (ICMC), Denton, U.S. (25 Sep.-1 Oct. 2015), pp. 372-375.

[10] D. Västfjäll, P. Larsson, and M. Kleiner "Emotion and Auditory Virtual Environments: Affect-Based Judgments of Music Reproduced with Virtual Reverberation Times," CyberPsychology \& Behavior, vol. 5, no. 1, pp. 19-32 (2002). doi: http://dx.doi.org/10.1089/ 109493102753685854

[11] A. Tajadura-Jiménez et al., "When Room Size Matters: Acoustic Influences on Emotional Responses to Sounds," Emotion, vol. 10, no. 3, pp. 416-422 (2010). doi: http://dx.doi.org/10.1037/a0018423

[12] R. Mo, B. Wu, and A. Horner "The Effects of Reverberation on the Emotional Characteristics of Musical Instruments," J. Audio Eng. Soc., vol. 63, pp. 966-979 (2016 Dec.). url: http://www.aes.org/elib/browse.cfm?elib=18055

[13] D. Williams "On the Affective Potential of the Recorded Voice," J. Audio Eng. Soc., vol. 64, pp. 429-437 (2016 Jun.). doi: http://dx.doi.org/ 10.17743/jaes.2016.0019

[14] K. Hevner, "Experimental Studies of the Elements of Expression in Music," Amer. J. Psych., pp. 246-268 (1936). doi: http://dx.doi.org/10.2307/1415746

[15] I. Peretz, L. Gagnon, and B. Bouchard "Music and Emotion: Perceptual Determinants, Immediacy, and Isolation after Brain Damage," Cognition , vol. 68, no. 2, pp. 111-141 (1998). doi: http://dx.doi.org/10.1016/S00100277

[16] G. Tzanetakis and P. Cook "Musical Genre Classification of Audio Signals," IEEE Transactions on Speech and Audio Processing, vol. 10, no. 5, pp. 293-302 (2002). doi: http://dx.doi.org/10.1109/TSA.2002.800560

[17] W. Ellermeier, M. Mader, and P. Daniel "Scaling the Unpleasantness of Sounds According to the BTL Model: Ratio-Scale Representation and Psychoacoustical Analysis," Acta Acustica United with Acustica, vol. 90, no. 1, pp. 101-107 (2004).

[18] J-J. Aucouturier, F. Pachet, and M. Sandler."'The Way it Sounds': Timbre Models for Analysis and Retrieval of Music Signals," Multimedia, IEEE Transactions on, vol. 7, no. 6, pp. 1028-1035 (2005). doi: http://dx.doi.org/10.1109/TMM.2005.858380

[19] E.1 Bigand et al., "Multidimensional Scaling of Emotional Responses to Music: The Effect of Musical Expertise and of the Duration of the Excerpts," Cognition \& Emotion, vol.19, no. 8, pp. 1113-1139 (2005). doi: http://dx.doi.org/10.1080/02699930500204250

[20] Y.-H. Yang et al., "A Regression Approach to Music Emotion Recognition," IEEE TASLP, vol. 16, no.
2, pp. 448-457 (May 15, 2009). doi: http://dx.doi.org/ 10.1109/tasl.2007.911513

[21] M. Zentner, D. Grandjean, and K. R. Scherer "Emotions Evoked by the Sound of Music: Characterization, Classification, and Measurement," Emotion, vol. 8, no. 4, p. 494 (2008). doi: http://dx.doi.org/10.1037/15283542.8.4.494

[22] J. C. Hailstone et al., "It's Not What You Play, It's How You Play I: Timbre Affects Perception of Emotion in Music," Quarterly J. Exper. Psych., vol. 62, no. 11, pp. 2141-2155 (2009). doi: http://dx.doi.org/10.1080/17470210902765957

[23] S. Filipic, B. Tillmann, and E. Bigand "Judging Familiarity and Emotion from Very Brief Musical Excerpts," Psychonomic Bulletin \& Review, vol. 17, no. 3, pp. 335-341 (2010). doi: http://dx.doi.org/ 10.3758/pbr.17.3.335

[24] C. L. Krumvansl "Plink: 'Thin Slices' of Music," Music Perception: An Interdisciplinary J., vol. 27, no. 5, p. 337-354 (2010). doi: http://dx.doi.org/10.1525/mp.2010.27.5.337

[25] T. Eerola and J. K. Vuoskoski "A Comparison of the Discrete and Dimensional Models of Emotion in Music," Psychology of Music, vol. 39, no. 1, pp. 18-49 (2011). doi: http://dx.doi.org/10.1177/0305735610362821

[26] J. K. Vuoskoski and T. Eerola "Measuring Music-Induced Emotion-A Comparison of Emotion Models, Personality Biases, and Intensity of Experiences," Musicae Sciential, vol. 15, no. 2, pp. 159-173 (2011). doi: http://dx.doi.org/10.1177/ 1029864911403367

[27] E. Asutay et al., "Emoacoustics: A Study of the Psychoacoustical and Psychological Dimensions of Emotional Sound Design," J. Audio Eng. Soc., vol. 60, pp. 21-28 (2012 Jan./Feb.).

[28] C. Baume "Evaluation of Acoustic Features for Music Emotion Recognition," presented at the 134th Convention of the Audio Engineering Society (2013 May), convention paper 8811 .

[29] Liebetrau Judith et al., "Paired Comparison as a Method for Measuring Emotions," presented at the 135th Convention of the Audio Engineering Society (2013 Oct.), convention paper 9016.

[30] L.-L. Balkwill and W. F. Thompson, "A CrossCultural Investigation of the Perception of Emotion in Music: Psychophysical and Cultural Cues," Music Perception, vol. 17, no. 1, pp. 43-64 (Fall 1999). doi: http://dx.doi.org/10.2307/40285811

[31] J. Skowronek, M. McKinney, and S. Van De Par "A Demonstrator for Automatic Music Mood Estimation," Proceedings of the International Conference on Music Information Retrieval (2007).

[32] I. Ekman and R. Kajastila "Localization Cues Affect Emotional Judgments-Results from a User Study on Scary Sound," presented at the AES 35th International Conference: Audio for Games (2009 Feb.), conference paper 23.

[33] Y. Hu, X. Chen, and D. Yang "LyricBased Song Emotion Detection with Affective Lexicon 
and Fuzzy Clustering Method," Proceedings of ISMIR (2009).

[34] J. Liebetrau, S. Schneider, and R. Jezierski "Application of Free Choice Profiling for the Evaluation of Emotions Elicited by Music," Proceedings of the 9th International Symposium on Computer Music Modeling and Retrieval (CMMR 2012): Music and Emotions, pp. 78-93 (2012).

[35] M. Plewa and B. Koster "A Study on Correlation between Tempo and Mood of Music," presented at the 133rd Convention of the Audio Engineering Society (2012 Oct.), convention paper 8800 .

[36] I. Lahdelma and T. Eerola, "Single Chords Convey Distinct Emotional Qualities to Both Naïve and Expert Listeners," Psychology of Music, vol. 44, no. 1, pp. 37-54 (2014). doi: http://dx.doi.org/10.1177/ 0305735614552006

[37] L. Cremer, H. A. Müller, and T. J. Schaultz Principles and Applications of Room Acoustics, vol. 1 (Applied Science New York, 1982).

[38] F. Ramsey "Reverberation and How to Remove It," J. Audio Eng. Soc., vol. 64, pp. 262-266 (2016 Apr.). url: http://www.aes.org/e-lib/browse.cfm?elib=18133

[39] McGill University, The Mcgill University Master Samples Collection on DVD (3 DVDs).

[40] Pros onus Shop, url: https://shop.presonus. com/products/software/notion-prods/notion-expansionbundles

[41] RWC Music Database, url: https://staff.aist. go.jp/m.goto/RWC-MDB/

[42] "University of Iowa Musical Instrument Samples," University of Iowa (2004). http://theremin.music. uiowa.edu/MIS.html

[43] R. Mo, G. L. Choi, C. Lee, and A. Horner, "The Effects of MP3 Compression on Emotional Characteristic," International Computer Music Conference (ICMC), Utrecht, 12 Sept - 16 Sept 2016, pp. 411-416.

[44] R. Mo, B. Wu, and A. Horner, "The Effects of Reverberation Time and Amount on the Emotional Characteristics," International Computer Music Conference (ICMC), Utrecht, 12 Sept - 16 Sept 2016, pp. 12-15.

[45] C.-j. Chau and A. Horner, "The Emotional Characteristics of Mallet Percussion Instruments with Different Pitches and Mallet Hardness," International Computer Music Conference (ICMC), Utrecht, 12 Sept - 16 Sept 2016, pp. 401-404
[46] S. J. M. Gilburt, C.-j. Chau, and A. Horner, "The Effects of Pitch and Dynamics on the Emotional Characteristics of Bowed String Instruments," International Computer Music Conference (ICMC), Utrecht, 12 Sept - 16 Sept 2016, pp. 405-410

[47] C.-j. Chau, R. Mo, and A. Horner, "The Emotional Characteristics of Piano Sounds with Different Pitch and Dynamics," J. Audio Eng. Soc., vol. 64, no.11, pp. 918-932 (2016), http://dx.doi.org/10.17743/jaes.2016.0049.

[48] J. W. Beauchamp "Analysis and Synthesis of Musical Instrument Sounds," Analysis, Synthesis, and Perception of Musical Sounds (Springer, 2007), pp. 1-89. doi: http://dx.doi.org/10.1007/978-0-387-32576-7_1

[49] T. Hidaka and L. L. Beranek "Objective and Subjective Evaluations of Twenty-Three Opera Houses in Europe, Japan, and the Americas," J. Acous. Soc. Am., vol. 107, no. 1, pp. 368-383 (2000). doi: http://dx.doi.org/10.1121/1.428309

[50] L. Beranek, Concert Halls and Opera Houses: Music, Acoustics, and Architecture (Springer Science \& Business Media, 2004). doi: http://dx.doi.org/10.1007/978-0387-21636-2

[51] "Cool Edit," Adobe Systems (2000). https://creative.adobe.com/products/audition

[52] P. N. Juslin and J. Slobodan Handbook of Music and Emotion: Theory, Research, Applications (Oxford University Press, 1993). doi: http://dx.doi.org/10.1093/ acprof:oso/9780199230143.001.0001

[53] M. M. Bradley and P. J. Lang, "Affective Norms for English Words (ANEW): Instruction Manual and Affective Ratings," Tech. Rep. (1999).

[54] Cambridge Academic Content Dictionary, url: http://dictionary.cambridge.org/dictionary/americanenglish

[55] R. A. Bradley "14 Paired Comparisons: Some Basic Procedures and Examples," Nonparametric Methods, vol. 4, pp. 299-326 (1984). doi: http://dx.doi.org/ 10.1016/s0169-7161(84)04016-5

[56] F. Wickelmaier and C. Schmid "A Matlab Function to Estimate Choice Model Parameters from PairedComparison Data," Behavior Research Methods, Instruments, and Computers, vol. 36, no. 1, pp. 29-40 (2004). doi: http://dx.doi.org/10.3758/bf03195547

[57] R. Mo et al., "The Effects of MP3 Compression on Perceived Emotional Characteristics in Musical Instruments," J. Audio Eng. Soc., vol. 64, pp. 858-867 (2016 Nov.). 


\section{APPENDIX A.}

Table 5. The normality of the data for each instrument and emotional characteristics for Anechoic. An absolute $\mathrm{Z}_{\text {skewness }}$ greater than 1.96 indicates a significant skew (i.e., either positively or negatively skewed) at $p<0.05$. An absolute $\mathrm{Z}_{\text {kurtosis }}$ greater than 1.96 indicates a significant kurtosis (i.e., either leptokurtic or platykurtic) at $p<0.05$.

\begin{tabular}{|c|c|c|c|c|c|c|c|c|}
\hline & \multicolumn{2}{|c|}{ Happy } & \multicolumn{2}{|c|}{ Heroic } & \multicolumn{2}{|c|}{ Comic } & \multicolumn{2}{|c|}{ Sad } \\
\hline & $Z_{\text {skewness }}$ & $\mathrm{Z}_{\text {kurtosis }}$ & $Z_{\text {skewness }}$ & $Z_{\text {kurtosis }}$ & $Z_{\text {skewness }}$ & $\mathrm{Z}_{\text {kurtosis }}$ & $Z_{\text {skewness }}$ & $\mathrm{Z}_{\text {kurtosis }}$ \\
\hline Bs & 0.95 & -0.29 & 1.51 & 0.35 & 0.96 & -0.24 & -1.33 & 0.06 \\
\hline $\mathrm{Cl}$ & 2.36 & 1.07 & 0.52 & -1.56 & 0.27 & -0.92 & -0.52 & -1.19 \\
\hline $\mathrm{Fl}$ & 0.82 & -0.87 & 0.93 & -0.50 & 1.31 & 1.03 & -1.50 & 0.29 \\
\hline $\mathrm{Hn}$ & 0.11 & -1.26 & 1.36 & -0.30 & 0.97 & -1.20 & -2.23 & 1.28 \\
\hline $\mathrm{Ob}$ & -1.53 & -1.19 & -1.73 & 0.52 & -0.10 & -0.37 & 0.56 & -0.42 \\
\hline Sx & 0.01 & -0.50 & -0.61 & -1.24 & -0.17 & -0.26 & -0.95 & -0.67 \\
\hline $\mathrm{Tp}$ & -0.24 & -1.05 & -2.09 & -0.75 & -1.80 & -0.37 & 1.09 & -1.51 \\
\hline \multirow[t]{3}{*}{$\mathrm{Vn}$} & 0.08 & -0.54 & -0.25 & -0.34 & -1.11 & 0.21 & 3.13 & 2.55 \\
\hline & \multicolumn{2}{|c|}{ Scary } & \multicolumn{2}{|c|}{ Shy } & \multicolumn{2}{|c|}{ Romantic } & \multicolumn{2}{|c|}{ Mysterious } \\
\hline & $\mathrm{Z}_{\text {skewness }}$ & $\mathrm{Z}_{\text {kurtosis }}$ & $\mathrm{Z}_{\text {skewness }}$ & $\mathrm{Z}_{\text {kurtosis }}$ & $Z_{\text {skewness }}$ & $\mathrm{Z}_{\text {kurtosis }}$ & $Z_{\text {skewness }}$ & $\mathrm{Z}_{\text {kurtosis }}$ \\
\hline Bs & 1.12 & -1.10 & -1.09 & 1.16 & 0.50 & -0.44 & -1.18 & -0.18 \\
\hline $\mathrm{Cl}$ & -0.44 & -0.69 & -2.65 & 1.70 & -1.53 & 0.76 & -1.01 & -0.98 \\
\hline $\mathrm{Fl}$ & 1.61 & 0.01 & -0.34 & 0.36 & -1.21 & -0.23 & -1.37 & -0.01 \\
\hline $\mathrm{Hn}$ & 0.54 & -1.27 & -1.99 & 0.13 & -0.75 & -1.38 & 0.07 & -0.92 \\
\hline $\mathrm{Ob}$ & 0.25 & -0.72 & 1.03 & -0.41 & 1.71 & -0.10 & -0.01 & -1.05 \\
\hline Sx & -0.26 & -0.84 & -0.10 & -0.25 & -0.87 & 0.25 & -0.16 & -1.05 \\
\hline $\mathrm{Tp}$ & -0.35 & -1.06 & 5.68 & 9.00 & 3.15 & 1.58 & 2.10 & -0.65 \\
\hline Vn & 0.18 & -0.81 & 1.06 & -1.33 & 1.36 & -0.07 & -0.67 & -1.12 \\
\hline
\end{tabular}

Table 6. The normality of the data for each instrument and emotional characteristics for Small Hall Front.

\begin{tabular}{|c|c|c|c|c|c|c|c|c|}
\hline & \multicolumn{2}{|c|}{ Happy } & \multicolumn{2}{|c|}{ Heroic } & \multicolumn{2}{|c|}{ Comic } & \multicolumn{2}{|c|}{ Sad } \\
\hline & $\mathrm{Z}_{\text {skewness }}$ & $\mathrm{Z}_{\text {kurtosis }}$ & $\mathrm{Z}_{\text {skewness }}$ & $\mathrm{Z}_{\text {kurtosis }}$ & $\mathrm{Z}_{\text {skewness }}$ & $\mathrm{Z}_{\text {kurtosis }}$ & $Z_{\text {skewness }}$ & $Z_{\text {kurtosis }}$ \\
\hline Bs & 0.56 & -1.05 & 0.05 & -0.62 & 0.34 & 0.58 & 0.01 & -0.29 \\
\hline $\mathrm{Cl}$ & 1.80 & 3.61 & 1.03 & -0.97 & 2.16 & 0.65 & -1.40 & -0.42 \\
\hline $\mathrm{Fl}$ & 0.04 & -1.22 & 0.55 & -1.00 & -0.49 & -0.07 & -0.07 & -0.64 \\
\hline $\mathrm{Hn}$ & 1.97 & 0.71 & 1.15 & -1.20 & 1.56 & 0.26 & -2.50 & 1.44 \\
\hline $\mathrm{Ob}$ & -0.43 & -0.96 & -1.80 & -0.66 & -2.43 & 3.45 & 0.68 & -0.83 \\
\hline $\mathrm{Sx}$ & -1.13 & 2.24 & 0.33 & -0.36 & 1.62 & -0.24 & -0.89 & -0.04 \\
\hline $\mathrm{Tp}$ & -2.07 & -0.36 & -1.93 & -0.76 & -1.18 & -1.01 & 0.94 & -1.33 \\
\hline \multirow[t]{3}{*}{ Vn } & -0.79 & -0.66 & -0.25 & 0.04 & -0.61 & 0.31 & 1.15 & -0.71 \\
\hline & \multicolumn{2}{|c|}{ Scary } & \multicolumn{2}{|c|}{ Shy } & \multicolumn{2}{|c|}{ Romantic } & \multicolumn{2}{|c|}{ Mysterious } \\
\hline & $\mathrm{Z}_{\text {skewness }}$ & $\mathrm{Z}_{\text {kurtosis }}$ & $Z_{\text {skewness }}$ & $\mathrm{Z}_{\text {kurtosis }}$ & $\mathrm{Z}_{\text {skewness }}$ & $\mathrm{Z}_{\text {kurtosis }}$ & $\mathrm{Z}_{\text {skewness }}$ & $\mathrm{Z}_{\text {kurtosis }}$ \\
\hline Bs & 0.11 & -1.05 & -0.31 & -0.80 & -1.20 & -0.35 & -0.63 & 0.73 \\
\hline $\mathrm{Cl}$ & -0.62 & -0.42 & -1.60 & 0.12 & -2.15 & 0.85 & -1.70 & 0.38 \\
\hline $\mathrm{Fl}$ & 0.68 & -1.05 & 0.67 & -1.19 & -1.20 & -0.24 & 0.38 & -0.79 \\
\hline $\mathrm{Hn}$ & -0.63 & -0.92 & -1.22 & -0.58 & -0.27 & -1.44 & 0.12 & -1.67 \\
\hline $\mathrm{Ob}$ & -0.79 & -0.75 & 1.87 & 0.06 & 1.50 & -0.98 & 0.52 & -0.23 \\
\hline $\mathrm{Sx}$ & 0.23 & -0.84 & -0.14 & -0.29 & -0.14 & -0.80 & 0.50 & -0.84 \\
\hline $\mathrm{Tp}$ & -0.53 & -0.75 & 2.02 & 0.61 & 3.53 & 3.01 & 2.57 & 0.10 \\
\hline $\mathrm{Vn}$ & 0.75 & -0.97 & 0.46 & -0.87 & 2.08 & 2.89 & -0.27 & -0.69 \\
\hline
\end{tabular}


Table 7. The normality of the data for each instrument and emotional characteristics for Small Hall Back.

\begin{tabular}{|c|c|c|c|c|c|c|c|c|}
\hline & \multicolumn{2}{|c|}{ Happy } & \multicolumn{2}{|c|}{ Heroic } & \multicolumn{2}{|c|}{ Comic } & \multicolumn{2}{|c|}{ Sad } \\
\hline & $Z_{\text {skewness }}$ & $Z_{\text {kurtosis }}$ & $Z_{\text {skewness }}$ & $\mathrm{Z}_{\text {kurtosis }}$ & $Z_{\text {skewness }}$ & $Z_{\text {kurtosis }}$ & $Z_{\text {skewness }}$ & $\mathrm{Z}_{\text {kurtosis }}$ \\
\hline Bs & -0.01 & -1.31 & 0.56 & -0.51 & 0.24 & -0.35 & -0.30 & -0.53 \\
\hline $\mathrm{Cl}$ & 0.84 & -0.38 & 1.71 & 0.23 & 2.15 & 1.27 & -2.02 & -0.26 \\
\hline $\mathrm{Fl}$ & -1.02 & -0.26 & 0.43 & 0.90 & 0.42 & -0.18 & -0.15 & 0.42 \\
\hline $\mathrm{Hn}$ & 2.05 & 0.40 & 0.25 & -1.09 & 1.45 & 0.36 & -1.36 & 0.34 \\
\hline $\mathrm{Ob}$ & -2.72 & 1.16 & -1.75 & -0.03 & -0.94 & -0.72 & 2.09 & 0.01 \\
\hline $\mathrm{Sx}$ & 0.76 & -1.31 & 0.68 & -0.34 & -1.29 & 0.87 & -1.22 & 0.10 \\
\hline $\mathrm{Tp}$ & -0.36 & -1.24 & -2.67 & 0.12 & -2.61 & 1.57 & 2.25 & 0.06 \\
\hline \multirow[t]{3}{*}{$\mathrm{Vn}$} & -0.11 & -0.24 & -0.20 & -1.04 & 0.48 & -0.41 & 2.12 & -0.07 \\
\hline & \multicolumn{2}{|c|}{ Scary } & \multicolumn{2}{|c|}{ Shy } & \multicolumn{2}{|c|}{ Romantic } & \multicolumn{2}{|c|}{ Mysterious } \\
\hline & $\mathrm{Z}_{\text {skewness }}$ & $\mathrm{Z}_{\text {kurtosis }}$ & $\mathrm{Z}_{\text {skewness }}$ & $\mathrm{Z}_{\text {kurtosis }}$ & $\mathrm{Z}_{\text {skewness }}$ & $\mathrm{Z}_{\text {kurtosis }}$ & $Z_{\text {skewness }}$ & $\mathrm{Z}_{\mathrm{kurtosis}}$ \\
\hline Bs & -0.13 & -1.05 & -1.85 & -0.47 & 0.37 & -1.00 & 0.74 & -0.32 \\
\hline $\mathrm{Cl}$ & -0.70 & -0.31 & -1.57 & -0.01 & -1.30 & -0.62 & -1.38 & -0.66 \\
\hline $\mathrm{Fl}$ & -0.17 & -0.42 & 0.85 & -1.21 & 0.06 & -1.29 & 0.78 & -0.83 \\
\hline $\mathrm{Hn}$ & 0.14 & -0.98 & -0.85 & -0.94 & -0.25 & -1.53 & -0.72 & -0.43 \\
\hline $\mathrm{Ob}$ & 1.07 & -0.71 & 0.80 & -0.32 & 1.76 & -0.81 & 2.87 & 0.73 \\
\hline $\mathrm{Sx}$ & -0.50 & -1.01 & 1.52 & 0.19 & 0.64 & -1.01 & 1.34 & -0.10 \\
\hline $\mathrm{Tp}$ & 0.05 & -1.70 & 1.04 & -1.43 & 1.47 & -1.27 & 0.57 & -1.29 \\
\hline Vn & -0.52 & -0.12 & 1.44 & -0.48 & 1.91 & 0.70 & -0.06 & -0.71 \\
\hline
\end{tabular}

Table 8. The normality of the data for each instrument and emotional characteristics for Large Hall Front.

\begin{tabular}{|c|c|c|c|c|c|c|c|c|}
\hline & \multicolumn{2}{|c|}{ Happy } & \multicolumn{2}{|c|}{ Heroic } & \multicolumn{2}{|c|}{ Comic } & \multicolumn{2}{|c|}{ Sad } \\
\hline & $Z_{\text {skewness }}$ & $Z_{\text {kurtosis }}$ & $Z_{\text {skewness }}$ & $\mathrm{Z}_{\text {kurtosis }}$ & $Z_{\text {skewness }}$ & $Z_{\text {kurtosis }}$ & $Z_{\text {skewness }}$ & $\mathrm{Z}_{\text {kurtosis }}$ \\
\hline Bs & -0.67 & 0.03 & 0.54 & -0.12 & 0.70 & -0.50 & -0.34 & -1.18 \\
\hline $\mathrm{Cl}$ & 2.22 & -0.19 & 1.57 & 0.65 & 1.36 & -0.89 & -1.26 & -0.03 \\
\hline $\mathrm{Fl}$ & 0.60 & 0.37 & 2.57 & 3.54 & -0.69 & -0.85 & -0.42 & 0.61 \\
\hline $\mathrm{Hn}$ & 1.60 & -0.46 & 0.63 & -0.84 & 2.11 & -0.07 & -2.12 & 0.58 \\
\hline $\mathrm{Ob}$ & -2.34 & 0.31 & -0.97 & -0.45 & -0.05 & -1.16 & 0.25 & -1.32 \\
\hline $\mathrm{Sx}$ & -0.12 & 1.17 & 0.77 & -0.40 & -1.01 & 0.00 & 0.74 & -1.52 \\
\hline $\mathrm{Tp}$ & -1.08 & -1.22 & -2.81 & 0.50 & -2.42 & 0.33 & 3.44 & 2.36 \\
\hline \multirow[t]{3}{*}{$\mathrm{Vn}$} & -1.30 & -0.40 & -0.91 & -0.35 & -0.32 & -0.59 & 0.16 & -0.46 \\
\hline & \multicolumn{2}{|c|}{ Scary } & \multicolumn{2}{|c|}{ Shy } & \multicolumn{2}{|c|}{ Romantic } & \multicolumn{2}{|c|}{ Mysterious } \\
\hline & $\mathrm{Z}_{\text {skewness }}$ & $\mathrm{Z}_{\text {kurtosis }}$ & $Z_{\text {skewness }}$ & $\mathrm{Z}_{\text {kurtosis }}$ & $Z_{\text {skewness }}$ & $\mathrm{Z}_{\text {kurtosis }}$ & $Z_{\text {skewness }}$ & $Z_{\text {kurtosis }}$ \\
\hline Bs & -1.18 & -0.93 & -2.19 & 1.53 & 0.19 & 0.60 & -0.17 & -0.87 \\
\hline $\mathrm{Cl}$ & -0.03 & -1.49 & 0.06 & -1.33 & -2.60 & 0.51 & -0.78 & -1.36 \\
\hline $\mathrm{Fl}$ & 0.61 & -1.23 & -1.69 & 1.16 & 0.79 & -1.15 & -0.48 & -0.27 \\
\hline $\mathrm{Hn}$ & 0.58 & -0.75 & -0.87 & -0.84 & -1.43 & 0.74 & -1.02 & -0.49 \\
\hline $\mathrm{Ob}$ & -1.32 & -1.29 & 0.20 & -1.33 & 1.34 & 1.07 & 0.52 & -1.32 \\
\hline $\mathrm{Sx}$ & -1.52 & -1.44 & 0.15 & -0.88 & 0.55 & -0.80 & -0.10 & 0.29 \\
\hline $\mathrm{Tp}$ & 2.36 & -1.92 & 2.70 & 0.41 & 2.26 & 3.06 & 2.67 & -0.03 \\
\hline Vn & -0.46 & -1.31 & 0.48 & -0.51 & 0.44 & -0.74 & 1.03 & 0.51 \\
\hline
\end{tabular}


Table 9. The normality of the data for each instrument and emotional characteristics for Large Hall Back.

\begin{tabular}{|c|c|c|c|c|c|c|c|c|}
\hline & \multicolumn{2}{|c|}{ Happy } & \multicolumn{2}{|c|}{ Heroic } & \multicolumn{2}{|c|}{ Comic } & \multicolumn{2}{|c|}{ Sad } \\
\hline & $Z_{\text {skewness }}$ & $\mathrm{Z}_{\text {kurtosis }}$ & $Z_{\text {skewness }}$ & $\mathrm{Z}_{\text {kurtosis }}$ & $Z_{\text {skewness }}$ & $Z_{\text {kurtosis }}$ & $Z_{\text {skewness }}$ & $\mathrm{Z}_{\text {kurtosis }}$ \\
\hline Bs & 0.07 & -1.29 & -0.74 & 0.96 & 0.22 & -0.55 & -0.87 & -0.24 \\
\hline $\mathrm{Cl}$ & 2.18 & 0.35 & 1.38 & -0.79 & 2.16 & 1.22 & -1.91 & 0.69 \\
\hline $\mathrm{Fl}$ & 0.79 & -1.29 & 0.54 & 0.28 & 0.56 & -0.91 & -1.30 & 1.94 \\
\hline $\mathrm{Hn}$ & 0.54 & -0.71 & 0.25 & -1.11 & 0.11 & -1.03 & -1.80 & 0.56 \\
\hline $\mathrm{Ob}$ & -1.26 & -1.42 & -0.82 & -0.33 & -0.91 & -0.66 & 1.50 & -0.27 \\
\hline $\mathrm{Sx}$ & -0.54 & -0.15 & -1.33 & 1.52 & -1.07 & -0.93 & -0.12 & 0.56 \\
\hline $\mathrm{Tp}$ & -0.97 & -0.35 & -1.80 & -0.08 & -1.37 & -0.22 & 1.42 & -0.33 \\
\hline \multirow[t]{3}{*}{$\mathrm{Vn}$} & -1.95 & 1.25 & -1.50 & 0.06 & 0.03 & -0.76 & 0.34 & -0.37 \\
\hline & \multicolumn{2}{|c|}{ Scary } & \multicolumn{2}{|c|}{ Shy } & \multicolumn{2}{|c|}{ Romantic } & \multicolumn{2}{|c|}{ Mysterious } \\
\hline & $Z_{\text {skewness }}$ & $\mathrm{Z}_{\text {kurtosis }}$ & $Z_{\text {skewness }}$ & $\mathrm{Z}_{\text {kurtosis }}$ & $Z_{\text {skewness }}$ & $\mathrm{Z}_{\text {kurtosis }}$ & $Z_{\text {skewness }}$ & $\mathrm{Z}_{\text {kurtosis }}$ \\
\hline Bs & 0.77 & -0.60 & -0.54 & -0.25 & -1.35 & 0.06 & -0.40 & -1.01 \\
\hline $\mathrm{Cl}$ & 0.33 & -1.03 & -0.91 & -0.05 & -2.07 & 0.90 & -1.81 & -0.19 \\
\hline $\mathrm{Fl}$ & 0.22 & -1.30 & 0.71 & -0.34 & 0.79 & -0.79 & -1.90 & 2.56 \\
\hline $\mathrm{Hn}$ & 0.76 & -0.80 & -0.78 & -0.07 & -0.58 & -0.82 & -1.21 & -0.02 \\
\hline $\mathrm{Ob}$ & 0.14 & -0.72 & 0.78 & -0.51 & 1.78 & 0.52 & 0.81 & -0.31 \\
\hline Sx & 0.73 & -1.07 & -0.36 & 0.00 & 0.93 & -0.59 & 0.34 & -0.95 \\
\hline $\mathrm{Tp}$ & -0.92 & -1.15 & 3.12 & 2.96 & 1.46 & -0.54 & 2.45 & -0.03 \\
\hline $\mathrm{Vn}$ & -0.84 & 0.92 & 0.96 & -0.98 & 1.47 & 0.23 & 0.49 & -0.25 \\
\hline
\end{tabular}




\section{APPENDIX B.}

Table 10. Based on Wilcoxon signed-rank tests, how often each instrument was statistically significantly greater (for $p<0.05$ ) than the others for each reverberation type and emotional characteristic. The maximum possible value is 7 and the minimum possible value is 0 . The maximum for each reverberation type and emotional characteristic is shown in bold.

\begin{tabular}{|c|c|c|c|c|c|c|c|c|c|c|c|c|c|c|c|c|}
\hline \multicolumn{9}{|c|}{ Anechoic } & \multicolumn{8}{|c|}{ Small Hall Front } \\
\hline & Bs & $\mathrm{Cl}$ & $\mathrm{Fl}$ & $\mathrm{Hn}$ & $\mathrm{Ob}$ & $\mathrm{Sx}$ & $\mathrm{Tp}$ & $\mathrm{Vn}$ & Bs & $\mathrm{Cl}$ & $\mathrm{Fl}$ & $\mathrm{Hn}$ & $\mathrm{Ob}$ & Sx & $\mathrm{Tp}$ & $\mathrm{Vn}$ \\
\hline Happy & 2 & 0 & 0 & 0 & 4 & 3 & 4 & 3 & 0 & 0 & 0 & 0 & 5 & 1 & 7 & 5 \\
\hline Heroic & 0 & 0 & 0 & 0 & 5 & 0 & 7 & 3 & 1 & 0 & 0 & 0 & 4 & 0 & 7 & 3 \\
\hline Comic & 0 & 0 & 0 & 0 & 4 & 2 & 7 & 2 & 0 & 0 & 0 & 0 & 6 & 3 & 6 & 4 \\
\hline $\mathrm{Sad}$ & 3 & 6 & 3 & 5 & 1 & 2 & 0 & 1 & 2 & 6 & 4 & 5 & 1 & 1 & 0 & 1 \\
\hline Scary & 0 & 1 & 0 & 0 & 1 & 1 & 1 & 2 & 0 & 0 & 1 & 0 & 0 & 0 & 0 & 1 \\
\hline Shy & 4 & 6 & 4 & 4 & 1 & 3 & 0 & 1 & 2 & 6 & 4 & 4 & 1 & 1 & 0 & 1 \\
\hline Romantic & 3 & 5 & 3 & 3 & 0 & 3 & 0 & 1 & 4 & 5 & 3 & 3 & 1 & 3 & 0 & 1 \\
\hline Mysterious & 0 & 6 & 5 & 1 & 0 & 0 & 0 & 0 & 1 & 5 & 1 & 1 & 0 & 1 & 0 & 1 \\
\hline \multicolumn{9}{|c|}{ Small Hall Back } & \multicolumn{8}{|c|}{ Large Hall Front } \\
\hline & Bs & $\mathrm{Cl}$ & $\mathrm{Fl}$ & $\mathrm{Hn}$ & $\mathrm{Ob}$ & $\mathrm{Sx}$ & $\mathrm{Tp}$ & $\mathrm{Vn}$ & Bs & $\mathrm{Cl}$ & $\mathrm{Fl}$ & $\mathrm{Hn}$ & $\mathrm{Ob}$ & Sx & $\mathrm{Tp}$ & Vn \\
\hline Happy & 1 & 0 & 0 & 0 & 4 & 3 & 4 & 3 & 3 & 0 & 0 & 0 & 5 & 2 & 5 & 5 \\
\hline Heroic & 1 & 0 & 0 & 1 & 6 & 2 & 7 & 2 & 2 & 0 & 1 & 1 & 3 & 2 & 7 & 2 \\
\hline Comic & 1 & 0 & 2 & 0 & 4 & 2 & 5 & 3 & 0 & 0 & 0 & 0 & 5 & 0 & 7 & 5 \\
\hline Sad & 3 & 5 & 5 & 5 & 1 & 2 & 0 & 1 & 4 & 4 & 4 & 4 & 1 & 3 & 0 & 1 \\
\hline Scary & 0 & 0 & 4 & 0 & 0 & 0 & 0 & 0 & 0 & 0 & 2 & 0 & 0 & 0 & 0 & 0 \\
\hline Shy & 4 & 6 & 5 & 1 & 1 & 1 & 0 & 1 & 3 & 7 & 4 & 3 & 1 & 3 & 0 & 1 \\
\hline Romantic & 3 & 5 & 3 & 3 & 1 & 3 & 0 & 1 & 3 & 5 & 3 & 4 & 0 & 3 & 0 & 0 \\
\hline Mysterious & 0 & 7 & 1 & 1 & 0 & 0 & 0 & 1 & 1 & 2 & 4 & 1 & 1 & 1 & 0 & 1 \\
\hline \multicolumn{9}{|c|}{ Large Hall Back } & & & & & & & & \\
\hline & Bs & $\mathrm{Cl}$ & $\mathrm{Fl}$ & $\mathrm{Hn}$ & $\mathrm{Ob}$ & $\mathrm{Sx}$ & $\mathrm{Tp}$ & $\mathrm{Vn}$ & & & & & & & & \\
\hline Happy & 1 & 0 & 1 & 0 & 4 & 1 & 6 & 1 & & & & & & & & \\
\hline Heroic & 2 & 0 & 1 & 2 & 2 & 2 & 7 & 3 & & & & & & & & \\
\hline Comic & 0 & 0 & 0 & 1 & 5 & 1 & 7 & 4 & & & & & & & & \\
\hline $\mathrm{Sad}$ & 4 & 6 & 4 & 6 & 0 & 2 & 0 & 0 & & & & & & & & \\
\hline Scary & 0 & 0 & 2 & 0 & 0 & 0 & 0 & 0 & & & & & & & & \\
\hline Shy & 4 & 7 & 4 & 4 & 1 & 1 & 0 & 1 & & & & & & & & \\
\hline Romantic & 4 & 5 & 3 & 4 & 1 & 2 & 0 & 1 & & & & & & & & \\
\hline Mysterious & 2 & 6 & 2 & 2 & 2 & 0 & 0 & 2 & & & & & & & & \\
\hline
\end{tabular}




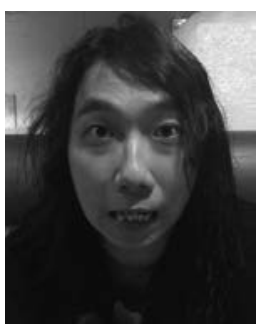

Ronald Mo

\section{THE AUTHORS}

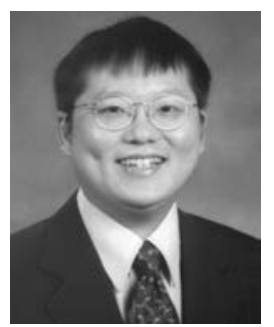

Prof. Richard So

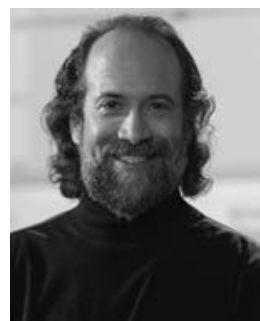

Andrew Horner
Ronald Mo is pursing his Ph.D. in computer science and engineering at the Hong Kong University of Science and Technology. His research interests include timbre of musical instruments, music emotion recognition, and digital signal processing. He received his B.Eng. in computer science and M.Phil. in computer science and engineering from the Hong Kong University of Science and Technology in 2007 and 2015 respectively.

Prof. Richard So received his B.Sc. degree (1987) in electronic engineering and Ph.D. degree (1995) in engineering and applied sciences from the Institute of Sound and Vibration Research (ISVR), University of Southampton, England. Prof. So is a professor of industrial engineering and logistics management and a professor in biomedical engineering at the Hong Kong University of Science and Technology. Prof. So's research focuses on visual and auditory perception. His recent projects include functional brain studies using near-infrared spectroscopic; visually induced motion sensations (VIMS); and binaural hearing. Besides fundamental research, Prof. So has also been actively involving in various consulting and industry-funded projects. Prof. So won the first Best Ergonomics Practitioner Award from the Hong Kong Ergonomics Society and received the honor title of the Chartered Fellow of the Institute of Ergonomics and Human Factors (UK) in 2011. He is currently serving as the Co-Editor-in-Chief of Displays, Editor of Ergonomics, and Scientific Editor of Applied Ergonomics. In 2014, he was elected as the Fellow of the International Ergonomics Association (IEA). This is a very prestigious Fellowship and Prof. So is the first recipient from Hong Kong; there were less than 100 senior academics worldwide holding the same title at the time of the election. In 2007, he found and chaired the First International Symposium on Visually Induced Motion Sensations (VIMS2007) and is on the Program Committees of VIMS2009, 2011, 2013 held (or to be held) in the Netherlands, US, and UK, respectively. In the midst of his research, Prof. So has also enjoyed teaching and was the recipient of the Teaching Excellence Appreciation Award.

Andrew Horner is a professor in the department of computer science and engineering at the Hong Kong University of Science and Technology. His research interests include music analysis and synthesis, timbre of musical instruments, and music emotion. He received his Ph.D. in computer science from the University of Illinois at UrbanaChampaign. 